\title{
A Modified Floor Field Model Combined with Risk Field for Pedestrian Simulation
}

\author{
Chao Wang and Jian Wang \\ School of Electronic and Information Engineering, Tongji University, Shanghai 201804, China \\ Correspondence should be addressed to Chao Wang; 890806wangchao@tongji.edu.cn
}

Received 2 November 2015; Revised 21 January 2016; Accepted 24 January 2016

Academic Editor: Evangelos J. Sapountzakis

Copyright (c) 2016 C. Wang and J. Wang. This is an open access article distributed under the Creative Commons Attribution License, which permits unrestricted use, distribution, and reproduction in any medium, provided the original work is properly cited.

\begin{abstract}
Microscopic evacuation models are of great value in both scientific research and practical applications. The floor field (FF) model is one of the most widely used models in previous research. However, the repulsion effect of hazard and the interaction between evacuees are not considered simultaneously. This paper proposes a modified floor field model combined with risk field and extended dynamic field to depict these features. The whole evacuation process is validated through a series of numerical simulations which are realized by $\mathrm{C}++$ language. In addition, two different renewal mechanisms, namely, synchronous and asynchronous renewal mechanisms, are compared to validate the model parameters. Results show that the proposed model is able to partly reveal the typical pedestrian behaviors and the impacts of hazard on evacuation process.
\end{abstract}

\section{Introduction}

In recent years, the number of accidents caused by crowded people or emergencies has increased year by year. These accidents not only result in huge economic losses to the society but also do serious damage to human life and property. However, it is generally known that evacuation exercise under emergency may cause unnecessary casualties and disaccord with ethics in real life. To solve this problem, computer modeling and simulation become substitutes with the development of computer science and technology.

Evacuation models can be split into two categories: the macroscopic models and the microscopic models [1]. In macroscopic model, the representative one is the fluiddynamic model $[2,3]$. In this kind of models, pedestrians are always described with fluid attributes and usually applied to the case of large crowd without thinking of their behaviors. Microscopic model can be further divided into two groups: continuous model with a representative of the social force (SF) model [4-9] and discrete model represented by the cellular automata (CA) model [10-15]. The floor field (FF) model is one of the most widely used CA models in emergency evacuation research and is first proposed by Burstedde et al. [10]. The proposed model consists of two fields: static field and dynamic field. During his research, the fermion is introduced to describe pedestrian's movement and the boson represents the pheromone particle. After that, lots of extended FF models are proposed by researchers in different aspects. Liao et al. [15] proposed FF model with the main static floor field and an extra substatic floor field to study the effects of the spatial distances from evacuees to the exits and the occupant densities around the exits upon the exitselection process. Zhao and $\mathrm{Li}$ [16] introduced game theory into FF model to study the inertia effects on strategy updating in emergency evacuation from a room with multiple exits. $\mathrm{Hu}$ et al. [17] proposed a novel three-dimensional cellular automata model with ladder factor. Wei et al. [18] put forward an idea of "virtual reference point" and propose a new method of building static floor field to solve the insufficient utilization of the exit region problem, while Xu et al. [19] pay attention to two cognitive coefficients of exit width and congestion degree around the exits to simulate the pedestrian evacuation behavior in a room with multiple exits.

These above-mentioned models seem to solve the problems under normal situation. Scholars have studied the emergency evacuation as well with considering disaster factors. Yang et al. [20] propose an agent-based model to research subway station fire and simulate the emergency evacuation 


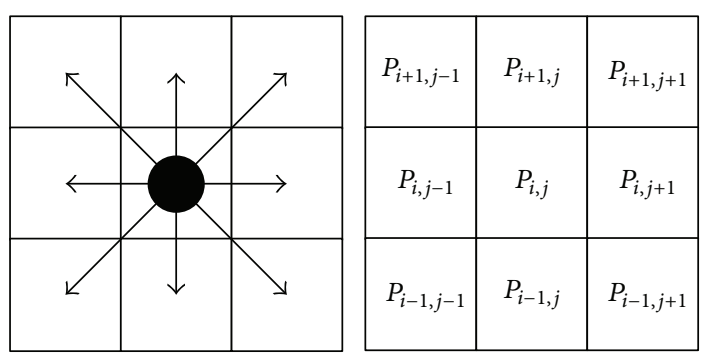

FIGURE 1: Moore neighborhood and the corresponding transition probability.

process. Smoke and fog effects are also studied by many researchers in various kinds of models [21-23]. Lei et al. [24] research the fire evacuation based on the factory of Jilin poultry company using the floor field model. In this paper, the fire location is regarded as a static obstacle and the influence of the shut-off of exits is illustrated. In one of our previous researches [25], we propose a dynamic field model to preliminarily investigate the effect of guiding information during evacuation. But the proposed FF model is used in normal situation which is insufficient to describe the effects of disaster on evacuees' exit choice behavior and the impact of disaster location on the total evacuation efficiency. Therefore, in this paper, we propose a risk field model to describe the disaster and the above-mentioned problems are researched through numerical simulation. In addition, Moore neighborhood is introduced to discretize the evacuation space (see Figure 1) and two different renewal mechanisms are also taken into account.

The remainder of this paper is organized as follows. First, in Section 2, we formulate our risk field model. Then, in Section 3, several simulations of an enclosed scenario based on the proposed methods are presented and the results are analyzed. Finally, in Section 4, we summarize the results and point out the future research.

\section{Models}

2.1. Static Floor Field Principles. According to the geometry of the room and door location, each cell is assigned a constant value representing its distance to the door. The closer the cell is to the exit, the smaller value it has. The static floor field of cell $(i, j)$ is denoted as $S^{\text {static }}(i, j)$ shown in Figure 2, which can be calculated as Varas et al. [26] proposed:

(1) The room is divided in a rectangular grid. The exit door is assigned a value of " 0. ."

(2) Then all adjacent cells to the previous one (a "second layer" of cells) are assigned a value according to the following rules:

(2.1) If a cell has value " $N$," the adjacent cells in the vertical or horizontal direction are " $N+1$ " and adjacent cells in diagonal directions are assigned a value of " $N+1.5$." This is a simple attempt to represent the fact that the distance between two diagonally adjacent cells is larger than that in horizontal or vertical directions.

(2.2) If there are conflicts in the assignment of a value to a cell, because it is adjacent to cells with different floor fields, then the minimum possible value is assigned to the cell in conflict.

(3) Then the third layer is calculated based on the second layer instead of the first layer.

(4) The process is repeated until all cells are evaluated.

(5) Cells represent walls and obstacles are given very high floor field values. This ensures that pedestrians will never attempt to occupy one of those cells. In this paper we choose 1000 as the value of the walls and fixed obstacles.

In the proposed model, basic principles for pedestrian movements and avoiding collision are based on the rules as follows:

(6) Each pedestrian chooses one of the eight adjacent cells at next time step depending on the transition probability algorithm (here the cell with the largest probability is chosen).

(7) When two or more evacuees choose the same cell as their target, this cell will be randomly assigned to one of these pedestrians.

2.2. Extended Dynamic Floor field Model. The dynamic floor field $D_{(i, j)}^{\text {dynamic }}(t)$ is inspired by the pheromone in chemotaxis initially proposed by Ben-Jacob [27]. Ben-Jacob proposed a dynamic floor field to translate long-ranged spatial interaction into an attractive local interaction, but with memory, similar to the phenomenon of chemotaxis in biology. Kirchner and Schadschneider [28] propose a dynamic floor field which indicates a virtual trace in the shape of boson left by the pedestrians. At $t$ time step for all cells of the discrete space, the dynamic field is zero; that is, $D_{(i, j)}^{\text {dynamic }}(t)=0$. Whenever a pedestrian jumps from cell $(i, j)$ to one of the neighboring cells, $D_{(i, j)}^{\text {dynamic }}(t)$ at the original cell is increased by one. In other words, whenever a person moves from cell $(i, j)$ to another cell $(x, y)$, he drops a boson at cell $(i, j)$; that is, $D_{(i, j)}^{\text {dynamic }}(t)=D_{(i, j)}^{\text {dynamic }}(t)+1$, and the value of $D_{(i, j)}^{\text {dynamic }}(t)$ at cell $(i, j)$ is the number of bosons. The boson has its 


\begin{tabular}{|c|c|c|c|c|c|c|c|c|c|c|c|c|c|c|c|c|c|c|c|c|c|c|c|c|c|c|c|c|c|}
\hline \multirow{2}{*}{\begin{tabular}{|l|l}
500 & 5 \\
500 & 1 \\
\end{tabular}} & \multirow{2}{*}{\begin{tabular}{c|c}
500 & 5 \\
13. & 1 \\
5 & \\
\end{tabular}} & \multirow{2}{*}{$\begin{array}{c}500 \\
12 . \\
5\end{array}$} & \multirow{2}{*}{\begin{tabular}{c|c}
500 & 5 \\
11. & 1 \\
5 & 1
\end{tabular}} & \multirow{2}{*}{\begin{tabular}{c|}
500 \\
10. \\
5
\end{tabular}} & \multirow{2}{*}{\begin{tabular}{c|c}
500 & 5 \\
9.5 & \\
\end{tabular}} & \multirow{2}{*}{\begin{tabular}{|l|}
500 \\
8.5
\end{tabular}} & \multirow{2}{*}{\begin{tabular}{c|}
500 \\
7.5 \\
\end{tabular}} & \multirow{2}{*}{\begin{tabular}{|l|}
500 \\
6.5 \\
\end{tabular}} & \multirow{2}{*}{\begin{tabular}{|l|}
500 \\
5.5 \\
\end{tabular}} & \multirow{2}{*}{\begin{tabular}{|l|}
500 \\
4.5 \\
\end{tabular}} & \multirow{2}{*}{\begin{tabular}{|l|}
500 \\
3.5 \\
\end{tabular}} & \multirow{2}{*}{\begin{tabular}{l|}
500 \\
2.5 \\
\end{tabular}} & \multirow{2}{*}{\begin{tabular}{|l|}
500 \\
1.5 \\
\end{tabular}} & \multicolumn{2}{|c|}{ Exit } & \multirow{2}{*}{\begin{tabular}{|c|}
500 \\
1.5 \\
\end{tabular}} & \multirow{2}{*}{\begin{tabular}{l|l}
500 & 5 \\
2.5 &
\end{tabular}} & \multirow{2}{*}{\begin{tabular}{c|c}
500 & 5 \\
3.5 &
\end{tabular}} & \multirow{2}{*}{\begin{tabular}{l|l}
500 & 5 \\
4.5 & 5
\end{tabular}} & \begin{tabular}{l|l}
500 & 5
\end{tabular} & 500 & 5005 & & 005 & & 500 & & & \\
\hline & & & & & & & & & & & & & & 1 & 1 & & & & & \begin{tabular}{l|l}
5.5 & 6 \\
\end{tabular} & 6.5 & 58 & 8.5 & 9.5 & \begin{tabular}{c|c}
10. & 1 \\
5 & \\
\end{tabular} & $\begin{array}{c}11 . \\
5\end{array}$ & $\begin{array}{c}12 . \\
5\end{array}$ & $\begin{array}{c}13 . \\
5\end{array}$ & 500 \\
\hline 500 & $\begin{array}{c}12 . \\
5\end{array}$ & 13 & 12 & 11 & 10 & 9 & 8 & 7 & 6 & 5 & 4 & 3 & 2.5 & & & 2.5 & 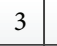 & 4 & 5 & 6 & 7 & 8 & 9 & 10 & \begin{tabular}{l|l}
11 & 1 \\
\end{tabular} & 12 & 13 & $\begin{array}{c}12 . \\
5\end{array}$ & 500 \\
\hline 00 & $\begin{array}{c}11 . \\
5\end{array}$ & 12 & $\begin{array}{c}12 . \\
5 \\
\end{array}$ & $\begin{array}{c}11 . \\
5 \\
\end{array}$ & $\begin{array}{c}10 . \\
5 \\
\end{array}$ & 9.5 & 8.5 & 7.5 & 6.5 & 5.5 & 4.5 & 4 & 3.5 & 4 & 4 & 3.5 & 4 & 4.5 & 5.5 & \begin{tabular}{l|l}
6.5 & 7 \\
\end{tabular} & \begin{tabular}{l|l}
7.5 & 8 \\
\end{tabular} & \begin{tabular}{l|l}
8.5 & 9
\end{tabular} & 9.5 & $\begin{array}{c}10 . \\
5\end{array}$ & \begin{tabular}{|c|c|}
11. & 1 \\
\end{tabular} & $\begin{array}{c}12 . \\
5 \\
\end{array}$ & 12 & $\begin{array}{c}11 . \\
5\end{array}$ & 500 \\
\hline ) & $\begin{array}{c}10 . \\
5\end{array}$ & 11 & $\begin{array}{c}11 . \\
5 \\
\end{array}$ & 12 & 11 & 10 & 9 & 8 & 7 & 6 & 5 & 5 & 5 & 5 & 5 & 5 & 5 & .5 & 6 & 7 & 8 & 9 & 10 & 11 & \begin{tabular}{l|l}
12 & 1 \\
\end{tabular} & $\begin{array}{c}11 . \\
5\end{array}$ & 11 & $\begin{array}{c}10 . \\
5\end{array}$ & 5 \\
\hline 0 & 9.5 & 10 & $\begin{array}{c}10 . \\
5 \\
\end{array}$ & 11 & $\begin{array}{c}11 . \\
5\end{array}$ & $\begin{array}{c}10 \\
5 \\
\end{array}$ & 9.5 & 8.5 & 7.5 & 7 & 6.5 & 6 & 5.5 & 6 & 6 & 5.5 & 6 & 6.5 & 77 & 7.5 & \begin{tabular}{l|l}
8.5 & 9
\end{tabular} & 9.5 & \begin{tabular}{c|c}
10. & 1 \\
5
\end{tabular} & $\begin{array}{c}11 . \\
5\end{array}$ & \begin{tabular}{l|l}
11 & 1 \\
\end{tabular} & $\begin{array}{c}10 . \\
5 \\
\end{array}$ & 10 & \begin{tabular}{c|c}
9.5 \\
\end{tabular} & 50 \\
\hline 0 & 8.5 & 9 & 9.5 & 10 & $\begin{array}{c}10 . \\
5\end{array}$ & 11 & 10 & 9 & 8.5 & 8 & 7.5 & 7 & .5 & 7 & 7 & 6.5 & 7 & 7.5 & 8 & 8.5 & \begin{tabular}{l|l}
9 & 1
\end{tabular} & 10 & \begin{tabular}{l|l}
11 & 1
\end{tabular} & $\frac{10 .}{5}$ & \begin{tabular}{l|l}
10 & 9
\end{tabular} & 9.5 & 9 & 8.55 & 500 \\
\hline 00 & 7.5 & 8 & 8.5 & 9 & 9.5 & \begin{tabular}{|l|}
10 \\
\end{tabular} & $\begin{array}{c}10 . \\
5 \\
\end{array}$ & 10 & 9.5 & 9 & 5 & 8 & 5 & 8 & 8 & 5 & 8 & 5 & 9 & .5 & \begin{tabular}{l|l}
10 & 1
\end{tabular} & $\begin{array}{c}10 . \\
5 \\
\end{array}$ & 10 & 9.5 & 0 & .5 & 8 & 5 & 5 \\
\hline 10 & 6.5 & 7 & 7.5 & 8 & 8.5 & 9 & 10 & 11 & $\begin{array}{c}10 . \\
5\end{array}$ & 10 & 9.5 & 9 & 8.5 & 9 & 9 & 8.5 & 9 & 9.5 & 10 & $\begin{array}{c}10 . \\
5\end{array}$ & \begin{tabular}{l|l}
11 & 1 \\
\end{tabular} & 10 & 9 & 8.5 & 7 & 7.5 & 7 & 6.55 & 50 \\
\hline 00 & 5.5 & 6 & 6.5 & 7 & 7.5 & 8.5 & 9.5 & 5. & $\begin{array}{c}11 . \\
5\end{array}$ & 11 & $\begin{array}{c}10 \\
5\end{array}$ & 10 & 9.5 & 10 & 10 & 9.5 & $10^{1}$ & $\begin{array}{c}10 . \\
5 \\
\end{array}$ & \begin{tabular}{l|l}
11 & 1 \\
\end{tabular} & $\begin{array}{c}11 . \\
5\end{array}$ & $\begin{array}{cc}10 . & 9 \\
5 & 9\end{array}$ & \begin{tabular}{l|l}
9.5 & 8
\end{tabular} & 8.57 & 7.5 & 7 & 6.5 & 6 & 5.5 & 5 \\
\hline 00 & 4.5 & 5 & 5.5 & 6 & 7 & 8 & 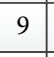 & 10 & 11 & 12 & $\begin{array}{c}11 \\
5\end{array}$ & 11 & $\begin{array}{c}10 . \\
5\end{array}$ & 11 & 1 & $\begin{array}{c}10 . \\
5\end{array}$ & 1 & $\begin{array}{c}11 . \\
5\end{array}$ & 12 & 11 & 10 & 0 & 8 & 7 & 5 & 5.5 & 5 & 4.5 & 5 \\
\hline 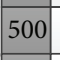 & 3.5 & 4 & 4.5 & 5 & 6.5 & 7.5 & 8.5 & 9.5 & $\begin{array}{c}10 . \\
5 \\
\end{array}$ & $\begin{array}{c}11 . \\
5\end{array}$ & $\begin{array}{c}12 \\
5\end{array}$ & 12 & 11. & 12 & 12 & 11. & 12 & $\begin{array}{c}5 \\
5\end{array}$ & \begin{tabular}{c|c}
11. & 1 \\
\end{tabular} & $\begin{array}{c}10 . \\
5\end{array}$ & \begin{tabular}{l|l}
9.5 & 8 \\
\end{tabular} & \begin{tabular}{l|l}
8.5 & 7
\end{tabular} & 7.5 & \begin{tabular}{l|l}
6.5 & 5 \\
\end{tabular} & \begin{tabular}{l|l}
5.5 & 4 \\
\end{tabular} & 4.5 & 4 & 3.5 & 5 \\
\hline 00 & 2. & 3 & 4 & 5 & 6 & 7 & 8 & 9 & 1 & 11 & 12 & 13 & $\begin{array}{c}12 . \\
5\end{array}$ & 13 & 13 & $\frac{12 .}{5}$. & 13 & 12 & 11 & 1 & 0 & 8 & 7 & 6 & 5 & 4 & 3 & .5 & 500 \\
\hline 0 & \begin{tabular}{|l|}
1.5 \\
\end{tabular} & .5 & 3.5 & 4.5 & 5.5 & 6.5 & 7.5 & 8.5 & \begin{tabular}{|l|}
9.5 \\
\end{tabular} & $\begin{array}{c}10 . \\
5\end{array}$ & $\begin{array}{c}11 \\
5\end{array}$ & $\begin{array}{c}12 . \\
5\end{array}$ & 13. & 14 & 14 & $\begin{array}{c}13 . \\
5\end{array}$ & 12 & $\begin{array}{c}11 . \\
5\end{array}$ & $\begin{array}{c}10 . \\
5\end{array}$ & .5 & \begin{tabular}{l|l}
8.5 & 7
\end{tabular} & \begin{tabular}{l|l}
7.5 & 6
\end{tabular} & 6.5 & \begin{tabular}{l|l}
5.5 & 4 \\
\end{tabular} & \begin{tabular}{l|l}
4.5 & 3
\end{tabular} & 3.5 & 5 & 1.5 & 5 \\
\hline & 1 & & 4 & 5 & 6 & 7 & 8 & 9 & 10 & 11 & 12 & 13 & 14 & 0 & 5 & 14 & 13 & 12 & 11 & 0 & 0 & & & 6 & & 4 & & 1 & \\
\hline & 1 & & 4 & 5 & 6 & 7 & 8 & 9 & 10 & 11 & 12 & 13 & 14 & 15 & 15 & 14 & 13 & 12 & 11 & 10 & 0 & 8 & 7 & 6 & 5 & 4 & & 1 & \\
\hline 00 & 1.5 & 2.5 & 3.5 & 4.5 & 5.5 & 6.5 & 7.5 & 8.5 & 9.5 & 5 & $\begin{array}{c}11 . \\
5\end{array}$ & $\begin{array}{c}12 . \\
5\end{array}$ & 13 & 14 & 14 & 5 & $\begin{array}{c}12 . \\
5\end{array}$ & $\begin{array}{c}11 . \\
5\end{array}$ & $\begin{array}{c}10 . \\
5\end{array}$ & \begin{tabular}{l|l}
9.5 & 8
\end{tabular} & \begin{tabular}{l|l}
8.5 & 7
\end{tabular} & \begin{tabular}{l|l}
7.5 & 6
\end{tabular} & 6.5 & \begin{tabular}{l|l}
5.5 & 4 \\
\end{tabular} & \begin{tabular}{l|l}
4.5 & 3
\end{tabular} & 3.5 & 2.5 & 1.5 & 500 \\
\hline 0 & 2.5 & 3 & 4 & 5 & 6 & 7 & 8 & 9 & 10 & 11 & 12 & 13 & $\begin{array}{c}12 . \\
5\end{array}$ & 13 & 13 & 12. & 13 & 12 & 11 & 10 & 9 & & & 6 & & 4 & 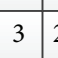 & 2.5 & 5 \\
\hline 1 & 3.5 & 4 & 4.5 & 5.5 & 6.5 & 7.5 & 8.5 & 9.5 & $\begin{array}{c}10 . \\
5 \\
\end{array}$ & $\begin{array}{c}11 . \\
5 \\
\end{array}$ & $\begin{array}{c}12 . \\
5 \\
\end{array}$ & 12 & $\begin{array}{c}11 . \\
5\end{array}$ & 12 & 12 & $\begin{array}{c}11 . \\
5\end{array}$ & 12 & $\begin{array}{c}12 . \\
5\end{array}$ & \begin{tabular}{r|r}
11. & 1 \\
5
\end{tabular} & 5 & 9.5 & 57 & 7.5 & 6.5 & \begin{tabular}{l|l}
5.5 & 4 \\
\end{tabular} & 4.5 & 4 & 3.5 & 5 \\
\hline 00 & 4.5 & 5 & 5.5 & 6 & 7 & 8 & & 10 & 11 & 12 & $\begin{array}{c}11 . \\
5\end{array}$ & 11 & $\begin{array}{c}10 . \\
5\end{array}$ & 11 & 11 & $\begin{array}{c}10 . \\
5\end{array}$ & \begin{tabular}{l|l}
11 \\
\end{tabular} & $\begin{array}{c}11 . \\
5\end{array}$ & 12 & 11 & 10 & 9 & 8 & 7 & \begin{tabular}{l|l}
6 & 5
\end{tabular} & 5.5 & 5 & 4.55 & 500 \\
\hline 00 & 5.5 & 6 & 65 & 7 & 7.5 & 8.5 & 9.5 & $\begin{array}{c}10 . \\
5\end{array}$ & $\begin{array}{c}11 . \\
5\end{array}$ & 11 & \begin{tabular}{|c|}
10 \\
5
\end{tabular} & 10 & 9.5 & 10 & 10 & 05 & 10 & $\begin{array}{c}10 . \\
5\end{array}$ & 1 & $\begin{array}{c}11 . \\
5\end{array}$ & $\begin{array}{c}10 . \\
5\end{array}$ & 058 & 3.5 & 75 & & 0.5 & & 5.55 & 500 \\
\hline 0 & 6.5 & 7 & 1.5 & 8 & 0.5 & 9 & 10 & 11 & $\begin{array}{c}10 . \\
5\end{array}$ & 10 & \begin{tabular}{|l|}
9.5 \\
\end{tabular} & 9 & 0.3 & (2) & ر & 3 & & 9.5 & 0 & $\begin{array}{c}10 . \\
5\end{array}$ & 11 & 10 & (3) & 0.5 & 0 & 7.5 & 7 & 0.5 & ב \\
\hline 00 & 7.5 & 8 & 8.5 & 9 & 9.5 & 10 & & 10 & 9.5 & 9 & 3.5 & 8 & 5 & 8 & 8 & 7.5 & 8 & 8.5 & 9 & 9.5 & 10 & & 10 & 9.5 & 9 & 8.5 & 8 & 7.55 & 500 \\
\hline 00 & 8 & 9 & 9. & 1 & $\begin{array}{c}10 . \\
5\end{array}$ & 11 & 10 & 9 & 8.5 & 8 & 7.5 & 7 & 6.5 & $\gamma$ & 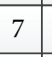 & 6.5 & & 5 & & & & 10 & 11 & $\begin{array}{c}10 . \\
5\end{array}$ & \begin{tabular}{l|l}
10 & 9
\end{tabular} & 9.5 & 9 & 8.55 & 500 \\
\hline 00 & 9.5 & 10 & $\begin{array}{c}0 . \\
5\end{array}$ & 11 & & $\begin{array}{c}10 . \\
5\end{array}$ & 9.5 & 8.5 & 7.5 & 7 & 6.5 & 6 & 5.5 & 0 & 6 & 5.5 & 6 & 6.5 & 7 & \begin{tabular}{l|l}
7.5 & 8
\end{tabular} & \begin{tabular}{l|l}
8.5 & 9
\end{tabular} & $9.55^{1}$ & 5 & $\begin{array}{c}11 \\
5\end{array}$ & \begin{tabular}{l|l}
11 & 1 \\
\end{tabular} & $\begin{array}{c}10 . \\
5\end{array}$ & 10 & 9.5 & 500 \\
\hline 00 & $\begin{array}{c}10 . \\
5\end{array}$ & 11 & $\begin{array}{c}11 . \\
5\end{array}$ & 12 & 11 & 10 & 9 & 8 & 7 & 6 & 5 & 5 & 4.5 & 5 & 5 & 5 & 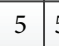 & 5 & 6 & 7 & 8 & 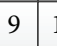 & 10 & 11 & \begin{tabular}{l|l}
12 & 1
\end{tabular} & $\frac{11 .}{5}$. & 11 & $\begin{array}{c}10 . \\
5\end{array}$ & 500 \\
\hline 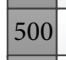 & 11. & 12 & $\begin{array}{c}12 . \\
5\end{array}$ & $\begin{array}{c}11 . \\
5\end{array}$ & $\begin{array}{c}10 . \\
5\end{array}$ & 9.5 & 8.5 & 7.5 & 6.5 & 5.5 & 4.5 & 4 & 3.5 & 4 & 4 & 3.5 & 4 & 4.5 & 0 & \begin{tabular}{l|l}
6.5 & 7 \\
\end{tabular} & \begin{tabular}{l|l}
7.5 & 8 \\
\end{tabular} & 8.59 & 9.5 & \begin{tabular}{c|c}
10. & 1 \\
5 &
\end{tabular} & \begin{tabular}{c|c}
11. & 1 \\
5 &
\end{tabular} & $\begin{array}{c}5 \\
5\end{array}$ & 2 & $\begin{array}{c}5 \\
11 . \\
5\end{array}$ & 500 \\
\hline 00 & $\begin{array}{c}12 \\
5\end{array}$ & 13 & 12 & 11 & 10 & 9 & 8 & 7 & 6 & 5 & 4 & 3 & 2.5 & & & 2.5 & 3 & 4 & 5 & 6 & 7 & 8 & 9 & 10 & \begin{tabular}{l|l}
11 & 1 \\
\end{tabular} & 12 & 13 & $\begin{array}{c}12 . \\
5\end{array}$ & 500 \\
\hline 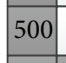 & $\begin{array}{c}13 . \\
5\end{array}$ & \begin{tabular}{|c|}
12. \\
5
\end{tabular} & $\begin{array}{c}11 . \\
5\end{array}$ & $\begin{array}{c}10 . \\
5\end{array}$ & 9.5 & 8.5 & 7 & 6.5 & 5.5 & 4.5 & 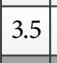 & . & 1.5 & 1 & 1 & 1.5 & & 3.5 & \begin{tabular}{l|l}
4.5 & 5
\end{tabular} & \begin{tabular}{l|l}
5.5 & 6
\end{tabular} & \begin{tabular}{l|l}
6.5 & 7
\end{tabular} & \begin{tabular}{l|l}
7.5 & 8
\end{tabular} & 8.5 & $5^{1}$ & \begin{tabular}{c|c}
10. & 1 \\
5 &
\end{tabular} & \begin{tabular}{|c|c|}
10. & 1 \\
5
\end{tabular} & $\begin{array}{c}12 . \\
5\end{array}$ & $\begin{array}{c}13 . \\
5\end{array}$ & 500 \\
\hline 00 & 500 & 500 & 500 & 500 & 500 & 500 & 500 & 500 & 500 & 500 & 500 & 500 & 500 & Exi & & 500 & 5005 & 5005 & 5005 & \begin{tabular}{l|l}
5005
\end{tabular} & 5005 & 5005 & 5005 & 5005 & \begin{tabular}{l|l}
5005 \\
\end{tabular} & 5005 & 5005 & 5005 & 500 \\
\hline
\end{tabular}

Figure 2: Distribution of static floor field. The evacuation space contains four exits with a value of " 0 " and each exit is composed of 2 cells (the green area). The outermost gray cells represent walls and are assigned a value of " 500 ." The black rectangle means obstacles and is assigned a value of " 500 " as well. The area marked with red is the proposed "hazard area" and we will give a detailed description in Section 2.2.

own dynamics, namely, diffusion and decay, which leads to broadening, dilution, and finally vanishing of the trace. In every time step, the bosons of cell $(i, j)$ diffuse and decay with probabilities $\alpha$ and $\delta$, respectively, so the extended dynamic floor field algorithm, the diffusion process, and decay process can be written as follows:

$$
D_{(i, j)}^{\text {dynamic }}=D_{(i, j)}^{\text {dynamic }}(t, \alpha, \delta) .
$$

Diffusion process is as follows:

$$
\begin{aligned}
& D_{(i, j)}^{\text {dynamic }}(t+1)=D_{(i, j)}^{\text {dynamic }}(t+0.5)-\alpha D_{(i, j)}^{\text {dynamic }}(t \\
& +0.5)+\frac{\alpha}{8}\left[D_{(i-1, j+1)}^{\text {dynamic }}(t+0.5)+D_{(i, j+1)}^{\text {dynamic }}(t+0.5)\right. \\
& +D_{(i+1, j+1)}^{\text {dynamic }}(t+0.5)+D_{(i-1, j)}^{\text {dynamic }}(t+0.5)
\end{aligned}
$$

$$
\begin{aligned}
& +D_{(i+1, j)}^{\text {dynamic }}(t+0.5)+D_{(i-1, j-1)}^{\text {dynamic }}(t+0.5) \\
& \left.+D_{(i, j-1)}^{\text {dynamic }}(t+0.5)+D_{(i+1, j-1)}^{\text {dynamic }}(t+0.5)\right] .
\end{aligned}
$$

Decay process is as follows:

$$
D_{(i, j)}^{\text {dynamic }}(t+0.5)=D_{(i, j)}^{\text {dynamic }}(t)-\delta D_{(i, j)}^{\text {dynamic }}(t) .
$$

The extended dynamic floor field after combination is as follows:

$$
\begin{gathered}
D_{(i, j)}^{\text {dynamic }}(t+1)=(1-\alpha)(1-\delta) D_{(i, j)}^{\text {dynamic }}(t) \\
+\frac{\alpha(1-\delta)}{8}\left[D_{(i-1, j+1)}^{\text {dynamic }}(t)+D_{(i, j+1)}^{\text {dynamic }}(t)\right.
\end{gathered}
$$




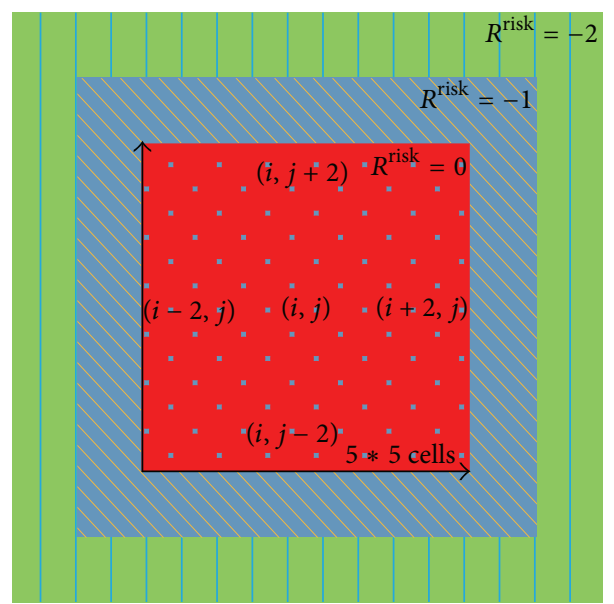

FIGURE 3: The sketch of risk field. $5 * 5$ red cells represent the hazard area with the maximum risk field value of " $R{ }^{\text {risk }} \equiv 0$. ." Then the outside blue cells are assigned a value of " -1 ;" in a similar way, the green cells are assigned a value of " -2 " and so on.

$$
\begin{aligned}
& +D_{(i+1, j+1)}^{\text {dynamic }}(t)+D_{(i-1, j)}^{\text {dynamic }}(t)+D_{(i+1, j)}^{\text {dynamic }}(t) \\
& \left.+D_{(i-1, j-1)}^{\text {dynamic }}(t)+D_{(i, j-1)}^{\text {dynamic }}(t)+D_{(i+1, j-1)}^{\text {dynamic }}(t)\right] .
\end{aligned}
$$

It is worth speaking that we take into account Moore neighborhood to describe the diffusion process which is different from Kirchner and Schadschneider's work [28]; see Figure 1. In this research, the dynamic floor field is abstracted as the creation, diffusion, and effect of evacuation information between evacuees. The evacuation information incorporates voice, gestures, and any of the other body languages pedestrian made but not the emergency exit sign and broadcast, which differs from our previous research [25].

2.3. Risk field. Lei et al. [24] research the fire evacuation based on the factory of Jilin poultry company using the floor field model and the fire location is regarded as a static obstacle. However, to our point of view, the repulsive effect of disaster and obstacle on pedestrian cannot be considered as equivalent in most emergency scenarios. Therefore, on account of evacuation authenticity, we establish a risk field instead of considering disaster as fixed obstacle. The rules for calculating dynamic risk field are listed as follows:

(1) The value of risk field is "0" until the hazard occurs.

(2) In the research of Yamamoto et al. [29], burning area is introduced and pedestrian is considered to evacuate keeping a constant distance $(0.4 \mathrm{~m}, 1.6 \mathrm{~m}$, and $2.8 \mathrm{~m}$, namely, 1 cell, 4 cells, and 7 cells) away from this area. Inspired by this research, we introduce a new concept which is called hazard area in this research. The hazard area centers on the accident point $(i, j)$ and contains 25 cells, that is, $(i \pm 2, j \pm 2)$.

(3) Cao et al. [30] propose a fire repulsive field which is calculated inversely proportional to the distance from the fire location. However, we consider that the repulsive effect of evacuee on disaster is the same in hazard area; therefore, we define that every cell in the hazard area acquires the maximum risk field value " $R^{\text {risk }} \equiv 0$." Then the value decreases one per one row or column; see Figure 3.

(4) If there are conflicts in the assignment of a value to a cell, because it is adjacent to cells with different risk fields caused by the other accident points, then the maximum possible value is assigned to the cell in conflict.

2.4. Transition Probability. The transition probability of a pedestrian is decided by the interaction of static floor field, dynamic floor field, and risk field. The transition probability $P_{(x, y)}$ of a pedestrian $i$ at time $t$ moving from cell $(i, j)$ to cell $(x, y)((x, y) \neq(i, j))$ can be calculated as follows:

$$
\begin{aligned}
& P_{(x, y)}=\xi_{(x, y)}\left(1-n_{(x, y)}\right) \\
& \quad \cdot \exp \left(-K_{S} \cdot S^{\text {static }}+K_{D} \cdot D^{\text {dynamic }}-K_{R} \cdot \Delta R^{\text {risk }}\right) .
\end{aligned}
$$

Pedestrian will move to a cell with larger transition probability. If all eight neighboring cells are occupied or the target cell is located in the hazard area, $P_{(x, y)}=0$. If a person is situated in the hazard area when accident occurs, he owns the top priority to move outside. The parameters $K_{S}, K_{D}$, and $K_{R}$ are the weight of $S^{\text {static }}, D^{\text {dynamic }}$, and $R^{\text {risk }}$, respectively, and $\Delta R^{\text {risk }}=R_{(x, y)}^{\text {risk }}-R_{(i, j)}^{\text {risk }}$. If a cell is occupied with a person, $n_{(x, y)}=1$; otherwise, $n_{(x, y)}=0$. Similarly, if a cell is occupied with a fixed obstacle, $\xi_{(x, y)}=0$; otherwise, $\xi_{(x, y)}=1$.

\section{Simulations}

The proposed model is mainly used to simulate pedestrian dynamics in a room with multiexit and multiaccident points. It is known that regular rooms are very common in many pedestrian facility structures, such as classrooms, office buildings, and laboratories. When emergency occurs, room is the first place we need to escape from. Therefore, modeling and 


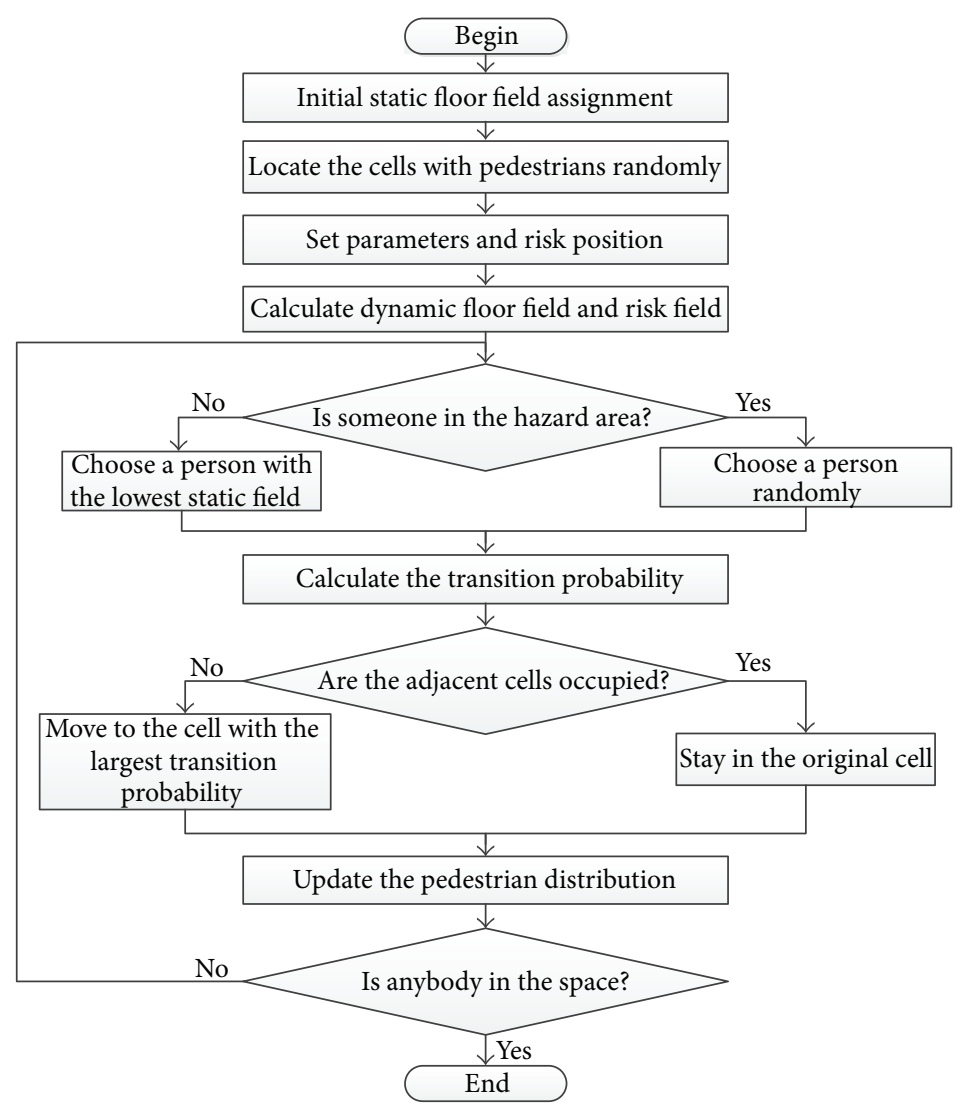

FIGURE 4: Flow chart of the simulation process.

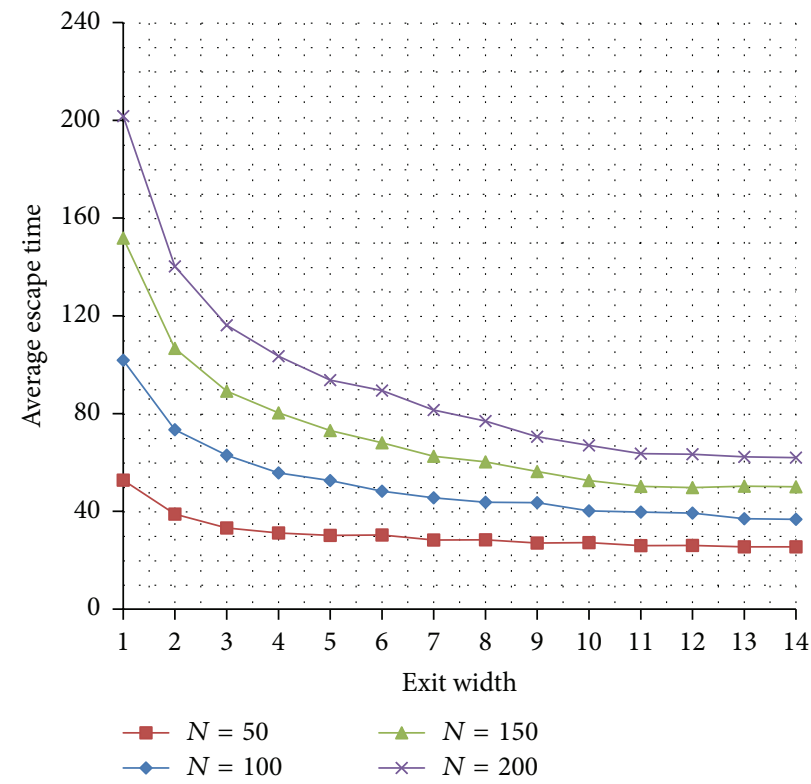

Figure 5: Correlation between the average escape time and exit width for a $16 * 20$ room with a door located in the left. $N$ is the number of evacuees that are initially distributed at random.

simulation of pedestrian dynamic in such scenario are of great significance. The simulation flow chart is shown in Figure 4.

Firstly, in order to detect our model, we consider a room of $16 * 20$ cells with $50,100,150$, and 200 persons initially distributed randomly, which is equivalent to those in previous research [26]. The exit is placed at the center of the left wall and the width is from one cell to 14 cells. The program is then repeated, and the evacuation time is calculated for different width of exit; see Figure 5. 500 times are averaged for each 


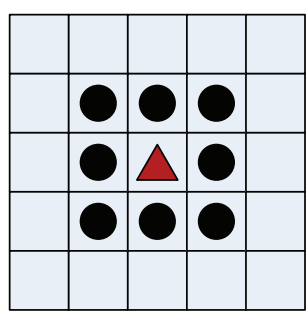

(a)

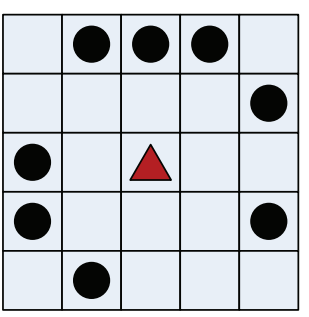

(b)

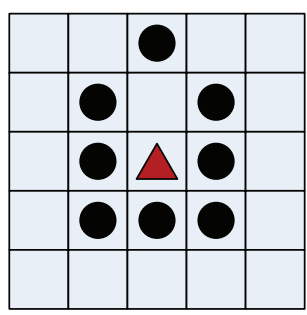

(c)

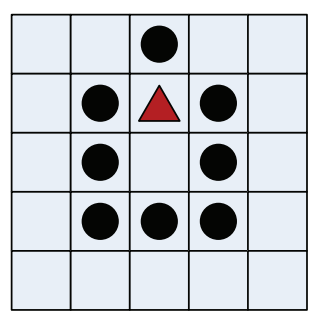

(d)

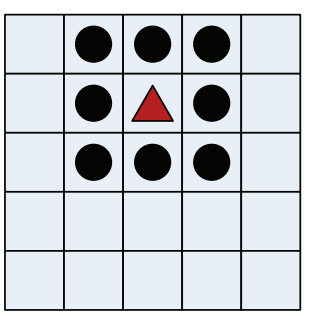

(e)

FIGURE 6: (a) The initial condition with 9 evacuees in 25 cells $(T=0)$. (b) In the scenario of synchronous renewal mechanism, 8 evacuees shaped with black circle move to the target cells in time step $1(T=1)$ and the middle red triangular shaped one stands still. (c) In the scenario of asynchronous renewal mechanism, one person moves to the upper cell in the first substep $(t=1)$. (d) In the second substep $(t=2)$, the red triangular shaped person moves to the cell occupied in the previous substep. (e) When 9 evacuees have moved to the target cells $(t=9)$ and the total time step plus one $(T=1)$.

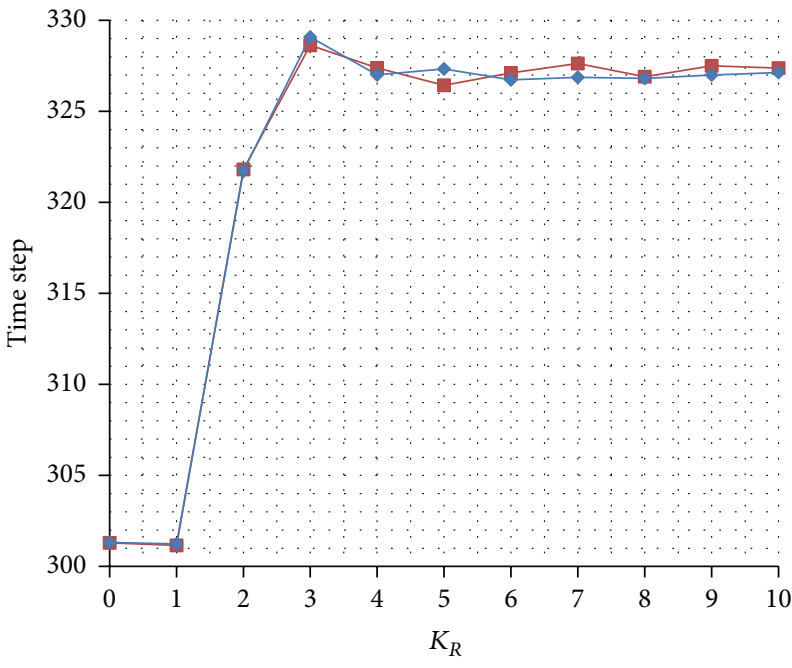

Synchronous Asynchronous

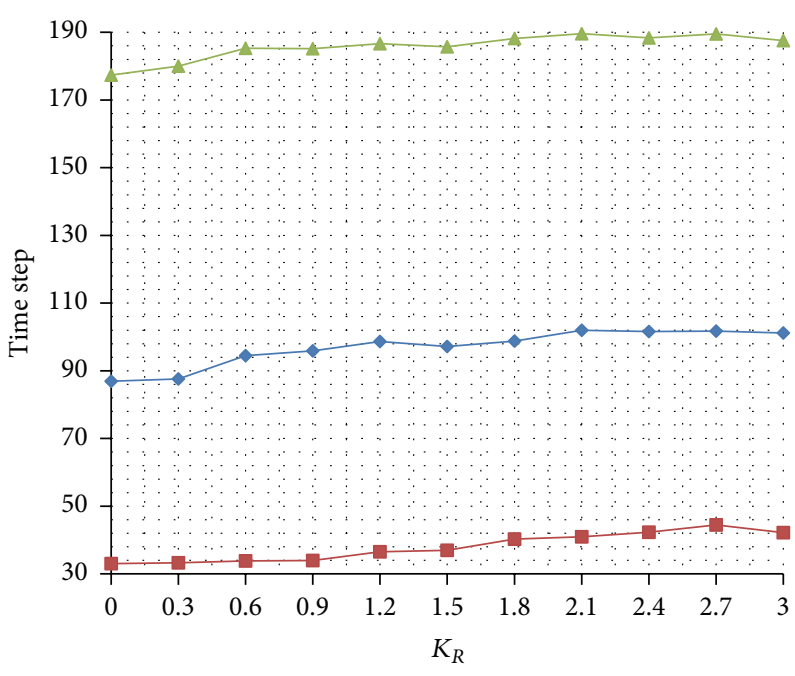

$-n=100$ $\triangle n=600$

(a)

(b)

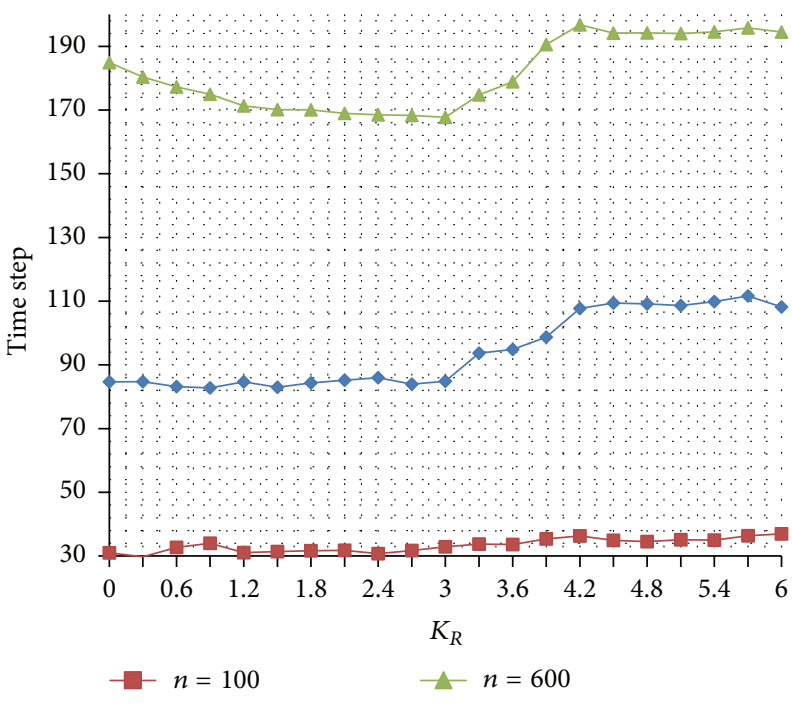

(c)

Figure 7: (a) 300 people with one exit on the upper wall and $K_{S}=K_{D}=1$. (b) Synchronous renewal mechanism with an exit on the middle of each wall and $K_{S}=1$, and $K_{D}=2$; " $n$ " is the number of evacuees. (c) Asynchronous renewal mechanism with an exit on the middle of each wall and $K_{S}=1$, and $K_{D}=2$. 


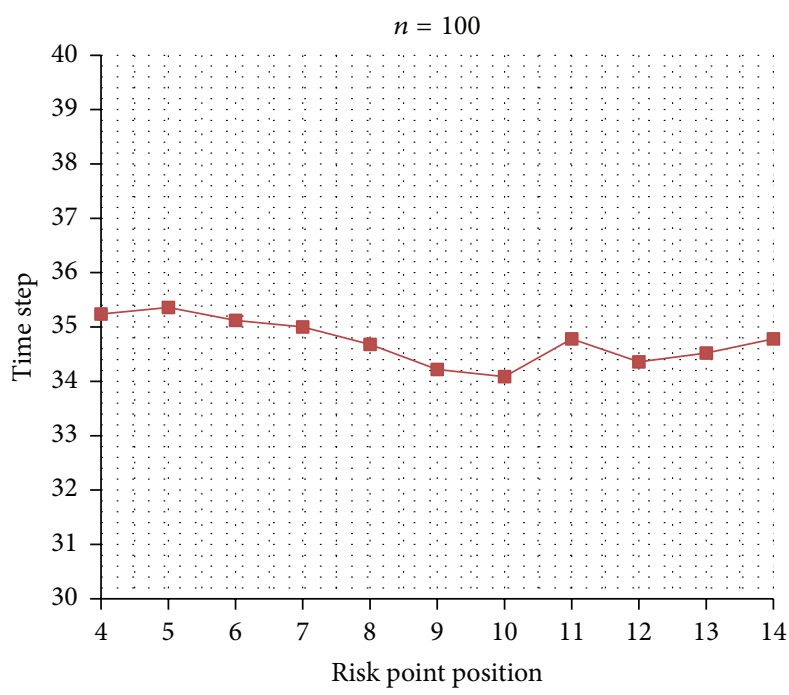

(a)

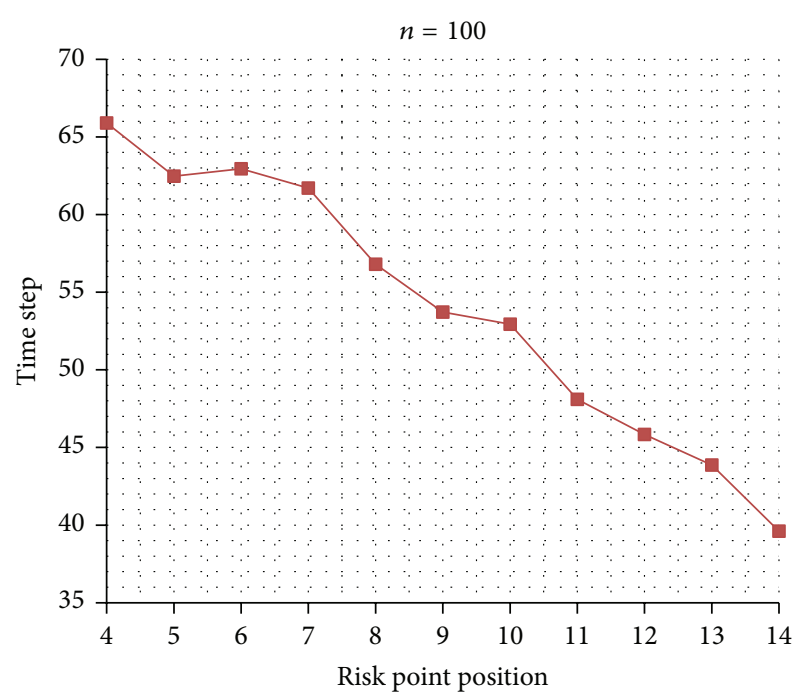

(b)

Figure 8: (a) Disaster is considered as a fixed obstacle [24], and $x$-axis represents the static floor field value of risk point. (b) Average escape time with considering risk field.

simulation due to the differing on the initial distribution of evacuees.

In Figure 6 we research the correlation between average escape time and exit width. The results show that escape time decreases with the increasing exit width, eventually tending towards stability. The statistical regulation of average escape time needs to be explained here. When pedestrian $i$ is located in the exit cell at time step T: (1) in our model, $i$ will be removed at the beginning of time step $T+1$ and the state of exit is refreshed to empty at the same; that is, this exit is able to be selected by other pedestrians at $T+1$; (2) Varas et al. [26] consider that $i$ will leave the room at $T+1$ and this exit can be selected as a target at $T+2$. In general, there is a difference of "evacuee number $(N)$ " between these two statistical regulations. Therefore, our results are identical to [26].

The validation is conducted with the synchronous renewal mechanism and the disaster factor is not yet considered. In the next chapter, we will do some experiments based on the proposed risk field model to research the impact of renewal mechanism on evacuation efficiency.

3.1. Renewal Mechanism. Two different renewal mechanisms are introduced in this research, namely, synchronous and asynchronous renewal mechanisms. In the scenario of synchronous renewal mechanism, every evacuee will choose an empty cell simultaneously as their target position. If two or more evacuees choose the same cell as their target in the same time step, the one who has the lowest static floor field will move first and the other competitors will stay in the current cell; furthermore, those surrounded by pedestrians will stay as well; see Figures 6(a) and 6(b). In the situation of asynchronous renewal mechanism, the time step will be divided into several substeps on the basis of the number of evacuees. The one with the lowest static floor field $(i, j)$ will be calculated in the first substep and moves to the target cell $(x, y)$ according to the result of transition probability. In the second substep, cell $(i, j)$ is considered as an empty cell and can be occupied once again; see Figures 6(a), 6(c), and $6(d)$.

In this scenario, the room is divided into $30 * 30$ cells with different positions and numbers of doors. The parameters are set as follows: $K_{S}=1, K_{D}=1,2$, and $K_{R}=$ $0,1,2,3,4,5,6,7,8,9,10$. The two renewal mechanisms are tested in the discrete square room and 500 simulations are averaged for each data point; see Figure 7.

In this simulation, the relationship between evacuation time and parameter $K_{R}$ in different renewal mechanisms is researched. Firstly, the scenario of 300 people with one exit on the middle of the upper wall is simulated and the coordinate of hazard point is $(14,14)$. As Figure 7 (a) shows, both two renewal mechanisms almost acquire the same result. On one hand, when the value of $K_{R}$ changes from 1 to 3, the number of total time steps increases obviously. On the other hand, with the increase of $K_{R}$ from 3 to 10 , the simulation time tends to be stable. In the situation of 4 doors distributed on each wall, there is a large difference between these two kinds of renewal mechanisms. In Figure 7(b), a series of simulations are tried, and the results show that synchronous mechanism is more suitable for the low density circumstance. More specifically, with the increase of $K_{R}$, the simulation time of 100 evacuees changes more obviously than that of 300 and 600 evacuees does. However, in the identical simulation scenario, synchronous renewal mechanism performs a contrary result. From Figure 7 (c), we find out that the simulation time step ends higher after initially falling and this phenomenon becomes more apparent with the increase of evacuees.

In summary, for multiexit circumstance, synchronous renewal mechanism is more suitable for low pedestrian density and the value of $K_{R}$ is more sensitive from 0 to 


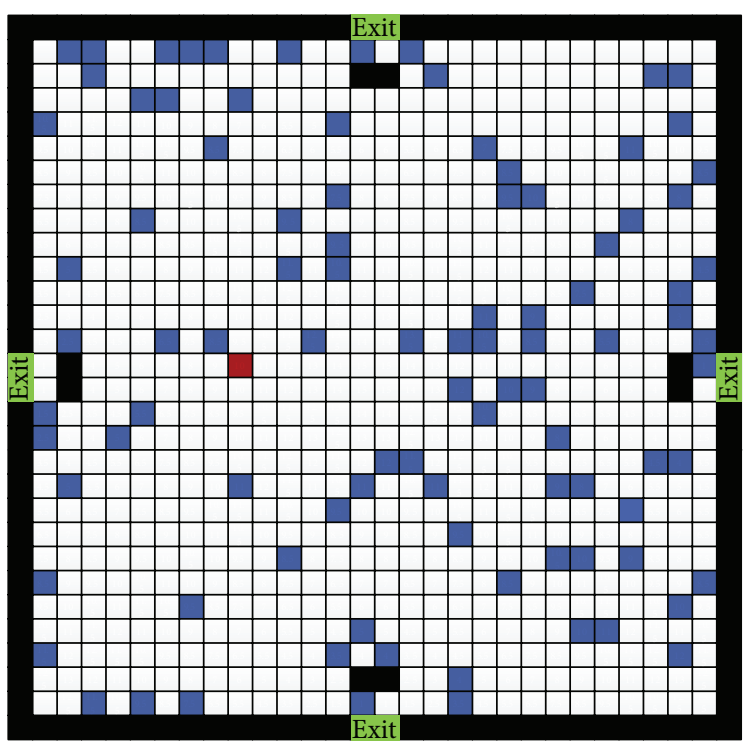

(a) $T=0$

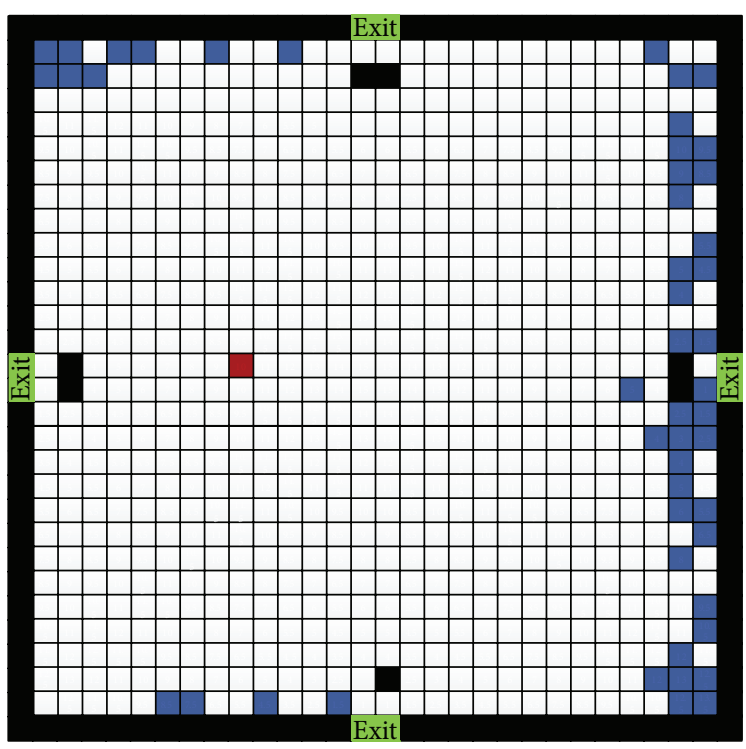

(c) $T=15$

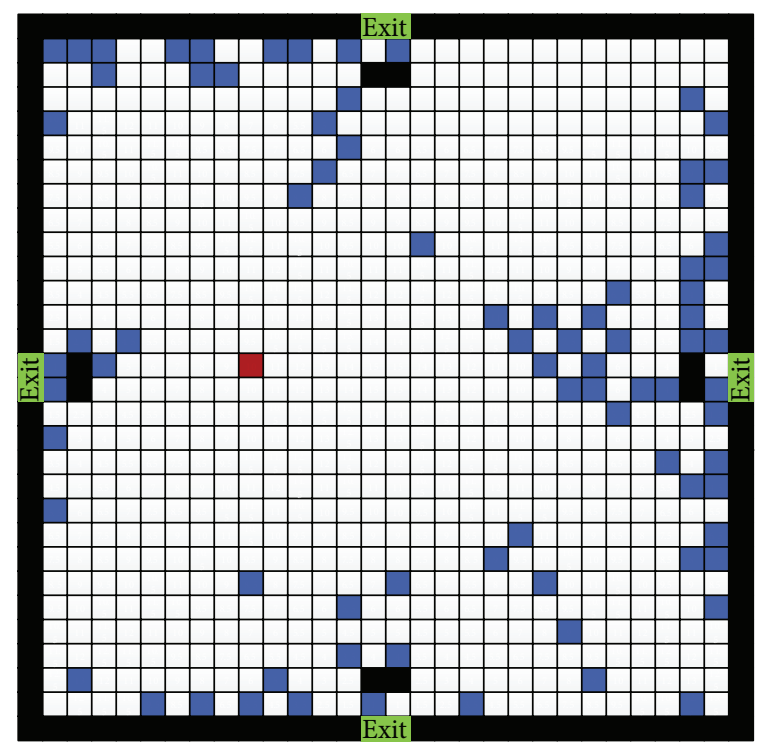

(b) $T=5$

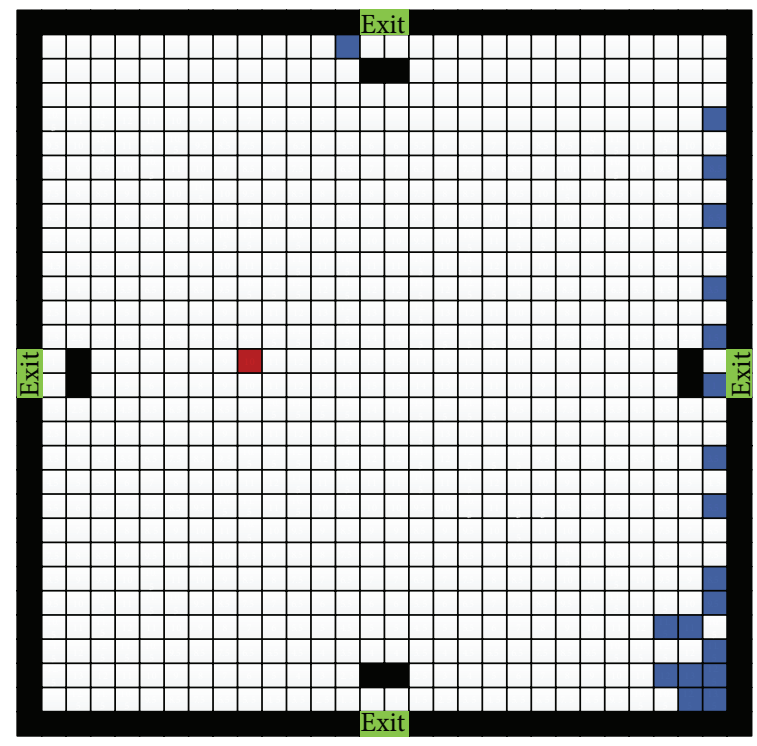

(d) $T=37$

FIGURE 9: The snapshots of simulation from $T=0$ to $T=37$. Green and red cells represent the exits and disaster location, respectively; the black cells depict the walls and obstacles; blue cells are evacuees.

approximately 3; moreover, synchronous renewal mechanism performs better in high density and the value of $K_{R}$ is susceptive from 0 to approximately 6 . Nevertheless, for one exit scenario, these two renewal mechanisms are similar to each other.

3.2. Distribution of Risk field. In this section, we try several simulations by using the synchronous renewal mechanism to research the relationship between the risk point position and evacuation time. The parameters are set as follows: $K_{S}=1$, $K_{D}=2$, and $K_{R}=2.4$, and the number of total evacuees is 100 . To illustrate the effect of risk field (see Figure 8), we firstly conduct a group of experiments with treating the hazard as a fixed obstacle [24]. As Figure 8(a) shows, the total time step is almost the same; in other words, the position of risk point has no influence on evacuation time. The results disagree with the facts.

When the risk field is introduced into the simulation, the results varied widely, possibly because of the repulsion effect; namely, when accident occurs the evacuees prefer to avoid the hazard. As the risk point becomes closer to the exit, there is a lower probability that the pedestrian will choose to leave from that exit.

In Figure 8(b), the total time step is inversely proportional to the distance between risk point and the exit. This phenomenon is more obvious when the value of risk point is 
greater than 7. This is possibly because 7 is the safety distance which evacuee considers; in other words, when the hazard is away from exit in certain distance, this exit is regarded as the safety exit. On the contrary, when accident occurs quite near the exit, almost no pedestrian is willing to leave from that egress except those nearby. Figure 9 shows parts of the evacuation process with considering risk effect.

" $T=0$ " is the initial state of the simulation, and 100 evacuees are distributed randomly. After 5 time steps, the right exit congests with the crowd, possibly because this exit is the farthest away from the accident point; in other words, the right exit is the safest and has the largest attraction to the evacuees. In addition, parts of the self-organization behaviors and phenomena are captured, for example, arching, lane formation, small groups, and repulsion of risk. When “ $T=15$," the crowd near the left exit are all evacuated and the left pedestrians move to the corner or the side. This is more authentic that evacuees always keep away from the accident instinctively and no one is willing to approach the risk once again and that is why the left exit remains empty during the remaining parts of the simulation. At time step 37, the arching phenomenon fades away; instead, evacuees choose to leave along the wall.

\section{Conclusions}

In this paper we have discussed the main properties of the modified floor field model for pedestrian dynamics and simulations which is composed of static field, risk field, and the extended dynamic field. The risk field is introduced to describe the repulsion effect of evacuees on disaster, while the extended dynamic field depicts the interaction between pedestrians. In addition, the impact of model parameters on evacuation efficiency under two different renewal mechanisms is discussed through numerical simulations. Concretely, in multiexit circumstance, synchronous renewal mechanism is more suitable for low pedestrian density and the synchronous renewal mechanism performs better in high density; in one exit scenario, these two renewal mechanisms are similar to each other. At last, the distance between exit and risk point is proved to be inversely proportional to the total evacuation time which is quite different with the research which considered the hazard as a fixed obstacle. Further research works will be continued and will focus on building the dynamic risk field model based on more observational research achievements while taking into account the congestion management.

\section{Conflict of Interests}

The authors declare that there is no conflict of interests regarding the publication of this paper.

\section{Authors' Contribution}

Chao Wang and Jian Wang proposed a modified floor field model combined with risk field; Chao Wang carried out the models and simulations and drafted the paper; Jian Wang made significant contributions during the development and finalization of the paper. Both of the authors read and approved the final paper.

\section{Acknowledgments}

The research work is partially supported by the National Natural Science Foundation of China (no. 71273188) and the Fundamental Research Funds for the Central Universities.

\section{References}

[1] N. Bellomo, B. Piccoli, and A. Tosin, "Modeling crowd dynamics from a complex system viewpoint," Mathematical Models and Methods in Applied Sciences, vol. 22, supplement 2, Article ID 1230004, pp. 1-29, 2012.

[2] L. F. Henderson, “The statistics of crowd fluids," Nature, vol. 229, no. 5284, pp. 381-383, 1971.

[3] R. L. Hughes, "A continuum theory for the flow of pedestrians," Transportation Research Part B: Methodological, vol. 36, no. 6, pp. 507-535, 2002.

[4] D. Helbing, I. Farkas, and T. Vicsek, "Simulating dynamical features of escape panic," Nature, vol. 407, no. 6803, pp. 487490, 2000.

[5] Y. Qu, Z. Gao, Y. Xiao, and X. Li, "Modeling the pedestrian's movement and simulating evacuation dynamics on stairs," Safety Science, vol. 70, pp. 189-201, 2014.

[6] G. Song and J. Park, "Discrete element method for emergency flow of pedestrian in S-type corridor," Journal of Nanoscience and Nanotechnology, vol. 14, no. 10, pp. 7469-7476, 2014.

[7] X. Yang, H. Dong, Q. Wang, Y. Chen, and X. Hu, "Guided crowd dynamics via modified social force model," Physica A. Statistical Mechanics and Its Applications, vol. 411, no. 10, pp. 63-73, 2014.

[8] W. Zeng, P. Chen, H. Nakamura, and M. Iryo-Asano, "Application of social force model to pedestrian behavior analysis at signalized crosswalk," Transportation Research Part C: Emerging Technologies, vol. 40, pp. 143-159, 2014.

[9] L. Hou, J.-G. Liu, X. Pan, and B.-H. Wang, "A social force evacuation model with the leadership effect," Physica A: Statistical Mechanics and its Applications, vol. 400, pp. 93-99, 2014.

[10] C. Burstedde, K. Klauck, A. Schadschneider, and J. Zittartz, "Simulation of pedestrian dynamics using a two-dimensional cellular automaton," Physica A: Statistical Mechanics and Its Applications, vol. 295, no. 3-4, pp. 507-525, 2001.

[11] D.-F. Xie, Z.-Y. Gao, X.-M. Zhao, and D. Z.-W. Wang, "Agitated behavior and elastic characteristics of pedestrians in an alternative floor field model for pedestrian dynamics," Physica A: Statistical Mechanics and Its Applications, vol. 391, no. 7, pp. 2390-2400, 2012.

[12] J. Tanimoto, A. Hagishima, and Y. Tanaka, "Study of bottleneck effect at an emergency evacuation exit using cellular automata model, mean field approximation analysis, and game theory," Physica A: Statistical Mechanics and Its Applications, vol. 389, no. 24, pp. 5611-5618, 2010.

[13] P. Yu-Cih and C. Chung-I, "Simulation of pedestrian flow through a "T" intersection-a multi-floor field cellular automata approach," Computer Physics Communications, vol. 182, no. 1, pp. 205-208, 2011. 
[14] J. Hu, H. Sun, G. Gao, J. Wei, and L. You, “The group evacuation behavior based on fire effect in the complicated threedimensional space," Mathematical Problems in Engineering, vol. 2014, Article ID 949280, 7 pages, 2014.

[15] W. Liao, X. Zheng, L. Cheng, Y. Zhao, Y. Cheng, and Y. Wang, "Layout effects of multi-exit ticket-inspectors on pedestrian evacuation," Safety Science, vol. 70, pp. 1-8, 2014.

[16] Y. Zhao and Y. Li, "Inertia effects on strategy updating in emergency evacuation from a room with multiple exits," International Journal of Modern Physics C, vol. 25, no. 9, pp. 1-9, 2014.

[17] J. Hu, L. You, J. Wei, M. Gu, and Y. Liang, "The effects of group and position vacancy on pedestrian evacuation flow model," Physics Letters A, vol. 378, no. 28-29, pp. 1913-1918, 2014.

[18] X. Wei, W. Song, W. Lv, X. Liu, and L. Fu, "Defining static floor field of evacuation model in large exit scenario," Simulation Modelling Practice and Theory, vol. 40, pp. 122-131, 2014.

[19] Y. Xu, H.-J. Huang, and G. Yong, "Modified static floor field and exit choice for pedestrian evacuation," Chinese Physics Letters, vol. 29, no. 8, Article ID 080502, 4 pages, 2012.

[20] P. Z. Yang, X. Wang, and T. Liu, "RETRACTED: agent-based simulation of fire emergency evacuation with fire and human interaction model," Safety Science, vol. 49, no. 8-9, pp. 1130-1141, 2011.

[21] W. Yuan and K. H. Tan, "A model for simulation of crowd behaviour in the evacuation from a smoke-filled compartment," Physica A: Statistical Mechanics and Its Applications, vol. 390, no. 23-24, pp. 4210-4218, 2011.

[22] E. N. M. Cirillo and A. Muntean, "Dynamics of pedestrians in regions with no visibility-a lattice model without exclusion," Physica A: Statistical Mechanics and Its Applications, vol. 392, no. 17, pp. 3578-3588, 2013.

[23] M. H. Nguyen, T. V. Ho, and J.-D. Zucker, "Integration of smoke effect and blind evacuation strategy (SEBES) within fire evacuation simulation," Simulation Modelling Practice and Theory, vol. 36, pp. 44-59, 2013.

[24] H. Lei, J.-G. Liu, X. Pan, Q. Guo, and B.-H. Wang, "Simulation of pedestrian evacuation based on Jilin fire," Acta Physica Sinica, vol. 63, no. 17, Article ID 178902, pp. 1-6, 2014.

[25] C. Wang, J. Wang, and Q. Bao, "A cellular automaton model based on dynamic floor-field for evacuation process with multiegress," in Proceedings of the IEEE International Conference on Systems, Man and Cybernetics (SMC '14), pp. 930-934, San Diego, Calif, USA, October 2014.

[26] A. Varas, M. D. Cornejo, D. Mainemer et al., "Cellular automaton model for evacuation process with obstacles," Physica A: Statistical Mechanics and Its Applications, vol. 382, no. 2, pp. 631642, 2007.

[27] E. Ben-Jacob, "From snowflake formation to growth of bacterial colonies II: cooperative formation of complex colonial patterns," Contemporary Physics, vol. 38, no. 3, pp. 205-241, 1997.

[28] A. Kirchner and A. Schadschneider, "Simulation of evacuation processes using a bionics-inspired cellular automaton model for pedestrian dynamics," Physica A: Statistical Mechanics and its Applications, vol. 312, no. 1-2, pp. 260-276, 2002.

[29] K. Yamamoto, S. Kokubo, H. Yamashita, and K. Nishinari, "Simulation of fire evacuation by Real-Coded Cellular Automata (RCA)," in Cellular Automata, vol. 5191 of Lecture Notes in Computer Science, pp. 447-454, Springer, Berlin, Germany, 2008.

[30] S.-C. Cao, W.-G. Song, X.-D. Liu, and N. Mu, "Simulation of pedestrian evacuation in a room under fire emergency," Procedia Engineering, vol. 71, pp. 403-409, 2014. 


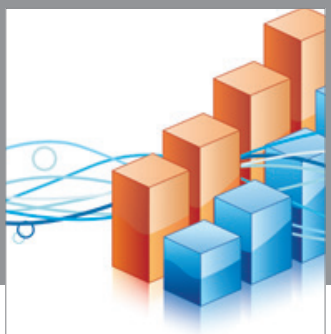

Advances in

Operations Research

vatem alat4

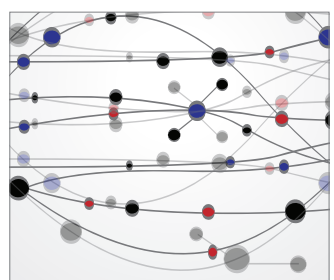

\section{The Scientific} World Journal
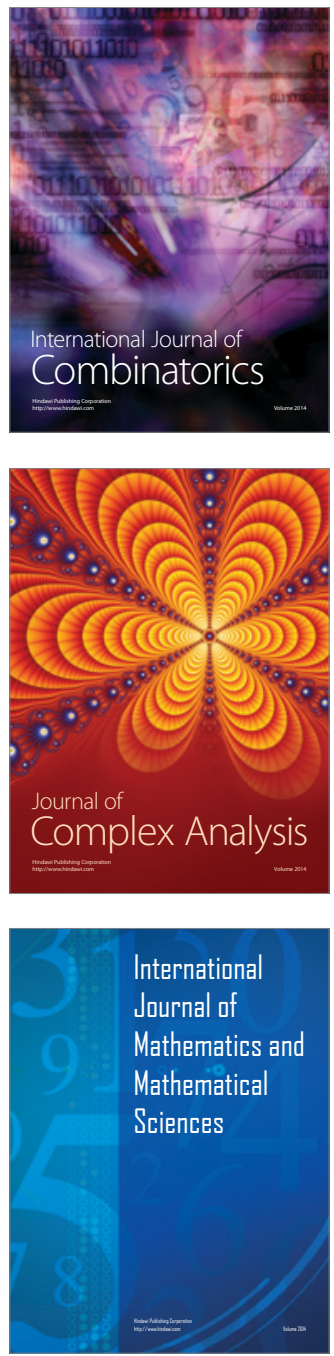
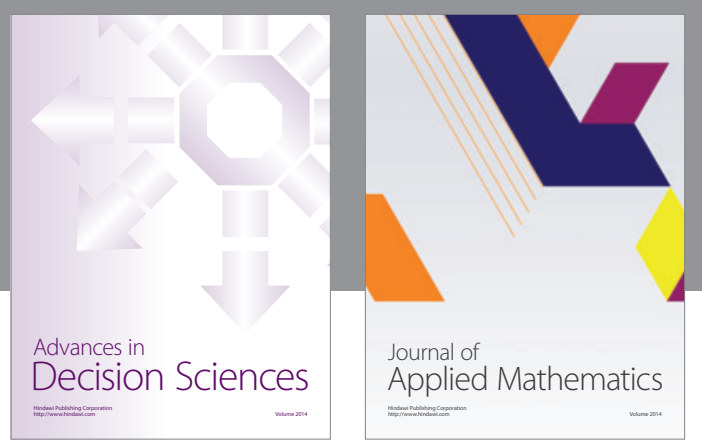

Algebra

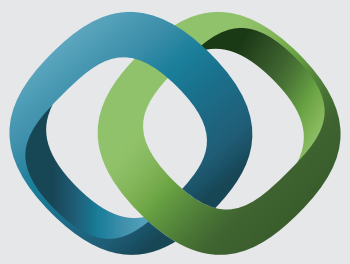

\section{Hindawi}

Submit your manuscripts at

http://www.hindawi.com
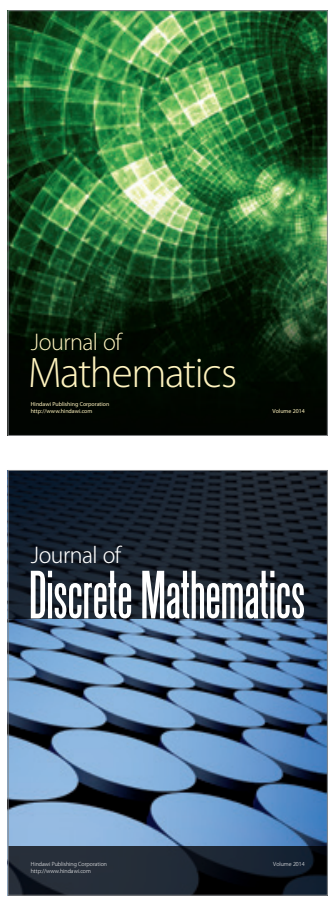

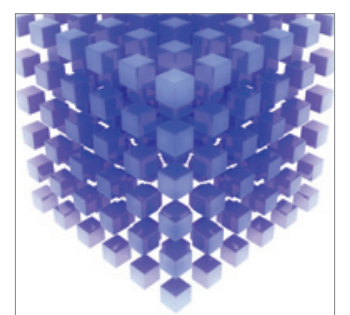

Mathematical Problems in Engineering
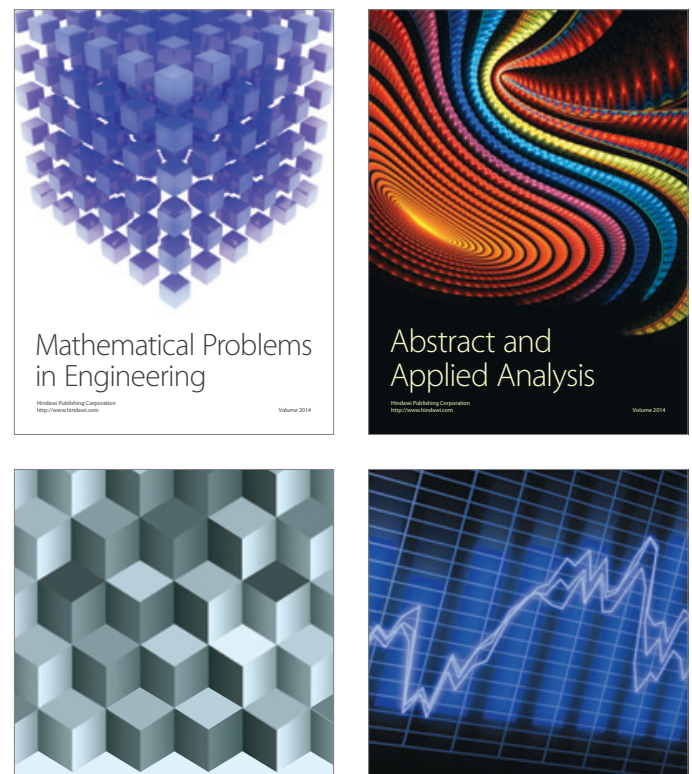

Journal of

Function Spaces

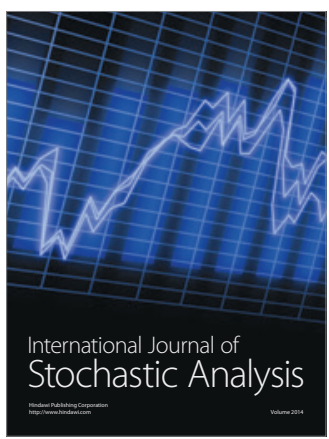

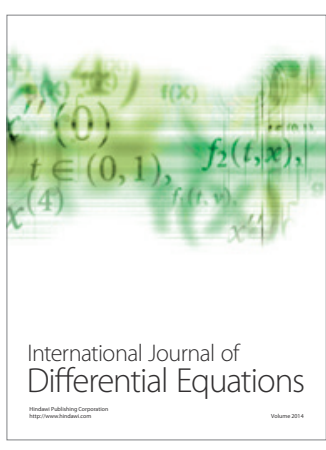
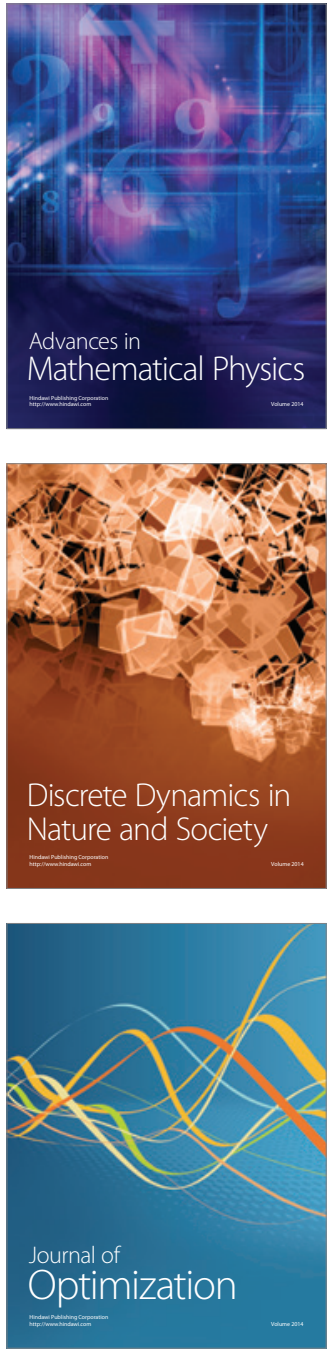